\title{
Article \\ Using Smart-WiFi Thermostat Data to Improve Prediction of Residential Energy Consumption and Estimation of Savings
}

\author{
Abdulrahman Alanezi *, Kevin P. Hallinan (D) and Rodwan Elhashmi \\ Department of Mechanical \& Aerospace Engineering, University of Dayton, Dayton, OH 45469-0238, USA; \\ kevin.hallinan@udayton.edu (K.P.H.); elhashmir1@udayton.edu (R.E.) \\ * Correspondence: alanezia1@udayton.edu
}

Citation: Alanezi, A.; P. Hallinan, K.; Elhashmi, R. Using Smart-WiFi

Thermostat Data to Improve Prediction of Residential Energy Consumption and Estimation of Savings. Energies 2021, 14, 187. https://doi.org/10.3390/en14010187

Received: 1 December 2020 Accepted: 29 December 2020 Published: 1 January 2021

Publisher's Note: MDPI stays neutral with regard to jurisdictional clai$\mathrm{ms}$ in published maps and institutional affiliations.

Copyright: ( 2021 by the authors. Licensee MDPI, Basel, Switzerland. This article is an open access article distributed under the terms and conditions of the Creative Commons Attribution (CC BY) license (https:// creativecommons.org/licenses/by/ $4.0 /)$.

\begin{abstract}
Energy savings based upon use of smart WiFi thermostats ranging from 10 to $15 \%$ have been documented, as new features such as geofencing have been added. Here, a new benefit of smart WiFi thermostats is identified and investigated; namely, as a tool to improve the estimation accuracy of residential energy consumption and, as a result, estimation of energy savings from energy system upgrades, when only monthly energy consumption is metered. This is made possible from the higher sampling frequency of smart WiFi thermostats. In this study, collected smart WiFi data are combined with outdoor temperature data and known residential geometrical and energy characteristics. Most importantly, unique power spectra are developed for over 100 individual residences from the measured thermostat indoor temperature in each and used as a predictor in the training of a singular machine learning models to predict consumption in any residence. The best model yielded a percentage mean absolute error (MAE) for monthly gas consumption $\pm 8.6 \%$. Applied to two residences to which attic insulation was added, the resolvable energy savings percentage is shown to be approximately $5 \%$ for any residence, representing an improvement in the ASHRAE recommended approach for estimating savings from whole-building energy consumption that is deemed incapable at best of resolving savings less than $10 \%$ of total consumption. The approach posited thus offers value to utility-wide energy savings measurement and verification.
\end{abstract}

Keywords: smart WiFi thermostats; machine learning; residential; energy consumption; energy savings

\section{Introduction}

The U.S. Energy Information Administration (EIA) estimates that the total U.S. natural gas consumption was about 32\% in 2019 of total energy consumption. The residential sector was responsible for $16 \%$ of this consumption [1] and $38 \%$ of the $\mathrm{CO}_{2}$ emissions in the U.S. [2]. Reducing reliance on fossil fuels in the short term remains an existential challenge for humanity. However, as a recent analysis by Stanford University documents, getting to $100 \%$ clean and renewable energy by 2050 requires a substantial reduction in energy demand (59\%) [3]. Essential in this process, as never before, is the ability to measure savings in order to validate the myriad of energy efficiency experiments which must be conducted. The most cost-effective energy reduction must learn from all actions. This is only possible if the means to estimate savings is certain.

Unfortunately, the state-of-the-art in measuring savings from energy improvements, short of individual real time metering, is inadequate, especially when energy consumption data is monthly. Presently, the approach recommended by ASHRAE in Guideline 14-2002, which leverages an inverse model based upon a simple three-parameter regression of monthly energy consumption with mean outdoor temperature for each meter period, suggests that savings of less than $10 \%$ cannot be resolved at best. More importantly, this savings estimation resolution depends upon the quality of the regression fit for an individual building or residence. It is likely that in most buildings, commercial or residential, this approach is unable to resolve energy savings well greater than $10 \%$ of consumption [4-7]. 
This paper above all explores use of smart WiFi thermostats to improve both the prediction of monthly energy consumption and, as a result energy savings from systems upgrades. Such technologies are now present in an estimated $11 \%$ of residences [8]. These thermostats measure and archive indoor temperature, setpoint temperatures for heating and cooling, and the status of the heating, cooling, and fan systems at sampling periods which can be as small as $1 \mathrm{~s}$. The research described herein specifically utilizes "delta" smart WiFi thermostat data from individual residences described in the prior research Lu et al. [9] and Huang et al. [10].

\section{Background}

Data analytics techniques have become a common means to analyze energy data. There has been a wealth of prior work in this area; all significantly reviewed by Amasyali et al. [2], Mosavi et al. [11] Seyedzadeh et al. [12], and Villa and Sassanelli [13]. Table 1 summarizes the most relevant of the research to predict different types of energy consumption at different data collection frequencies. The frequencies associated with the energy consumption types have ranged from hourly, to daily, to monthly. Included in the table, in addition to the data collection frequency, is also information about the learning algorithm, predictors used, target or response variable, building type, and quality of the prediction.

Table 1. Summary of prior research in predicting energy consumption in residential buildings.

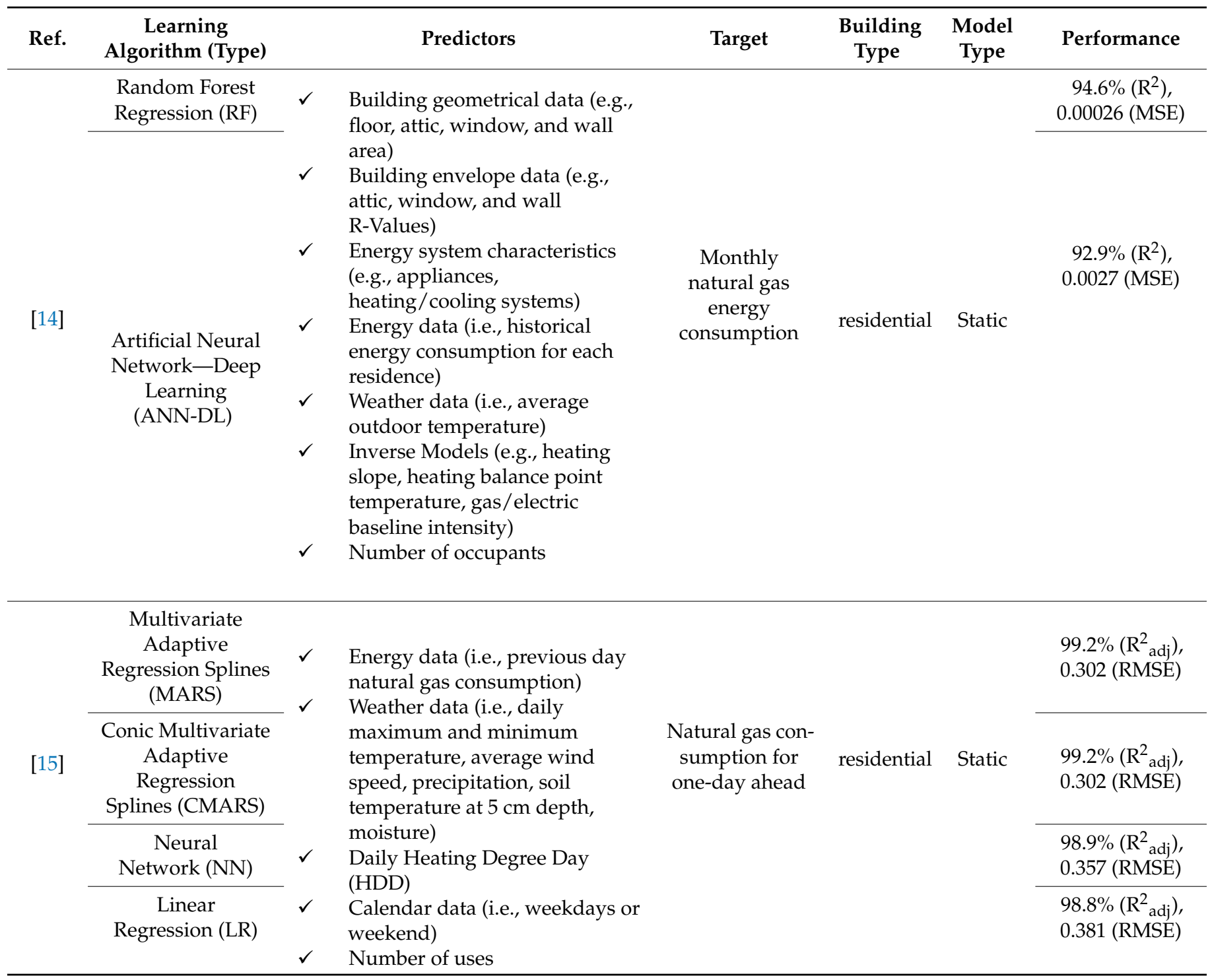


Table 1. Cont.

\begin{tabular}{|c|c|c|c|c|c|c|c|}
\hline Ref. & $\begin{array}{c}\text { Learning } \\
\text { Algorithm (Type) }\end{array}$ & & Predictors & Target & $\begin{array}{l}\text { Building } \\
\text { Type }\end{array}$ & $\begin{array}{l}\text { Model } \\
\text { Type }\end{array}$ & Performance \\
\hline \multirow{4}{*}{ [22] } & $\begin{array}{l}\text { Support Vector } \\
\text { Machine (SVM) }\end{array}$ & \multirow[t]{4}{*}{$\checkmark$} & \multirow{4}{*}{$\begin{array}{l}\text { Building envelope data (i.e., } \\
\text { walls and roof R-Values, } \\
\text { building size coefficient } \\
\text { integrated shading coefficient, } \\
\text { thermal inert index of building } \\
\text { walls, }(\mathrm{E}, \mathrm{W}, \mathrm{S} \text {, and } \mathrm{N} \text { ) } \\
\text { window-wall ratio, shading } \\
\text { coefficient of (E, W, S, and N) } \\
\text { window, and exterior walls } \\
\text { absorption coefficient for } \\
\text { solar radiation) }\end{array}$} & \multirow{4}{*}{$\begin{array}{l}\text { Annual } \\
\text { electricity } \\
\text { consumption }\end{array}$} & \multirow{4}{*}{ residential } & \multirow{4}{*}{ Static } & 0.0239 (RMSE) \\
\hline & $\begin{array}{l}\text { Artificial Neural } \\
\text { Network-Back } \\
\text { Propagation } \\
\text { (ANN-BP) }\end{array}$ & & & & & & 0.1446 (RMSE) \\
\hline & $\begin{array}{l}\text { Artificial Neural } \\
\text { Network-Radial } \\
\text { Basis Function } \\
\text { (ANN-RBF) }\end{array}$ & & & & & & 0.1244 (RMSE) \\
\hline & $\begin{array}{l}\text { Artificial Neural } \\
\text { Network- } \\
\text { General } \\
\text { Regression } \\
\text { (ANN-GR) }\end{array}$ & & & & & & 0.0524 (RMSE) \\
\hline [16] & $\begin{array}{c}\text { Multiple Linear } \\
\text { Regression (MLR) }\end{array}$ & $\begin{array}{l}\checkmark \\
\checkmark \\
\checkmark\end{array}$ & $\begin{array}{l}\text { Energy data (i.e., historical } \\
\text { electricity load) } \\
\text { Weather data (i.e., forecasting } \\
\text { daily outdoor temperature) } \\
\text { Calendar data (i.e., the day of } \\
\text { the week) }\end{array}$ & $\begin{array}{l}\text { Electricity } \\
\text { consumption } \\
\text { for one } \\
\text { day ahead }\end{array}$ & residential & Static & $\begin{array}{l}\text { 12.39\% (MAPE), } \\
2.39 \mathrm{kWh} / \text { day } \\
(\mathrm{RMSE})\end{array}$ \\
\hline [23] & $\begin{array}{l}\text { Artificial Neural } \\
\text { Network-Back } \\
\text { Propagation } \\
\text { (ANN-BP) }\end{array}$ & $\checkmark$ & $\begin{array}{l}\text { Geography data (i.e., } \\
\text { orientation) } \\
\text { Building envelope data (i.e., } \\
\text { insulation thickness, and } \\
\text { building transparency ratio) }\end{array}$ & $\begin{array}{c}\text { Annual } \\
\text { building } \\
\text { heating energy }\end{array}$ & $\mathrm{N} / \mathrm{S}$ & Static & $\begin{array}{l}\text { average } \\
\text { 94.8-98.5\% } \\
\text { accuracy } \\
\text { compared with } \\
\text { numerical } \\
\text { results }\end{array}$ \\
\hline \multirow[t]{2}{*}{ [17] } & $\begin{array}{l}\text { Support Vector } \\
\text { Machine (SVM) }\end{array}$ & \multirow[t]{2}{*}{$\checkmark$} & \multirow[t]{2}{*}{$\begin{array}{l}\text { Weather data (i.e., hourly } \\
\text { dry-bulb temperature, relative } \\
\text { humidity, and solar } \\
\text { radiation intensity) }\end{array}$} & \multirow[t]{2}{*}{$\begin{array}{l}\text { Hourly } \\
\text { building } \\
\text { cooling load }\end{array}$} & \multirow[t]{2}{*}{ Mixed } & \multirow[t]{2}{*}{$\begin{array}{l}\text { Multi- } \\
\text { step }\end{array}$} & $\begin{array}{l}\text { Jul: } 0.006 \\
\text { (RMSE) } \\
\text { May: } 1.146 \\
\text { (RMSE) } \\
\text { Jun: } 1.157 \\
\text { (RMSE) } \\
\text { Aug: } 1.168 \\
\text { (RMSE) } \\
\text { Oct: } 1.182 \\
\text { (RMSE) }\end{array}$ \\
\hline & $\begin{array}{l}\text { Artificial Neural } \\
\text { Network-Back } \\
\text { Propagation } \\
\text { (ANN-BP) }\end{array}$ & & & & & & $\begin{array}{c}\text { Jul: } 0.008 \\
\text { (RMSE) } \\
\text { May: } 2.302 \\
\text { (RMSE) } \\
\text { Jun: } 2.321 \\
\text { (RMSE) } \\
\text { Aug: } 2.223 \\
\text { (RMSE) } \\
\text { Oct: } 2.365 \\
\text { (RMSE) }\end{array}$ \\
\hline
\end{tabular}


Table 1. Cont.

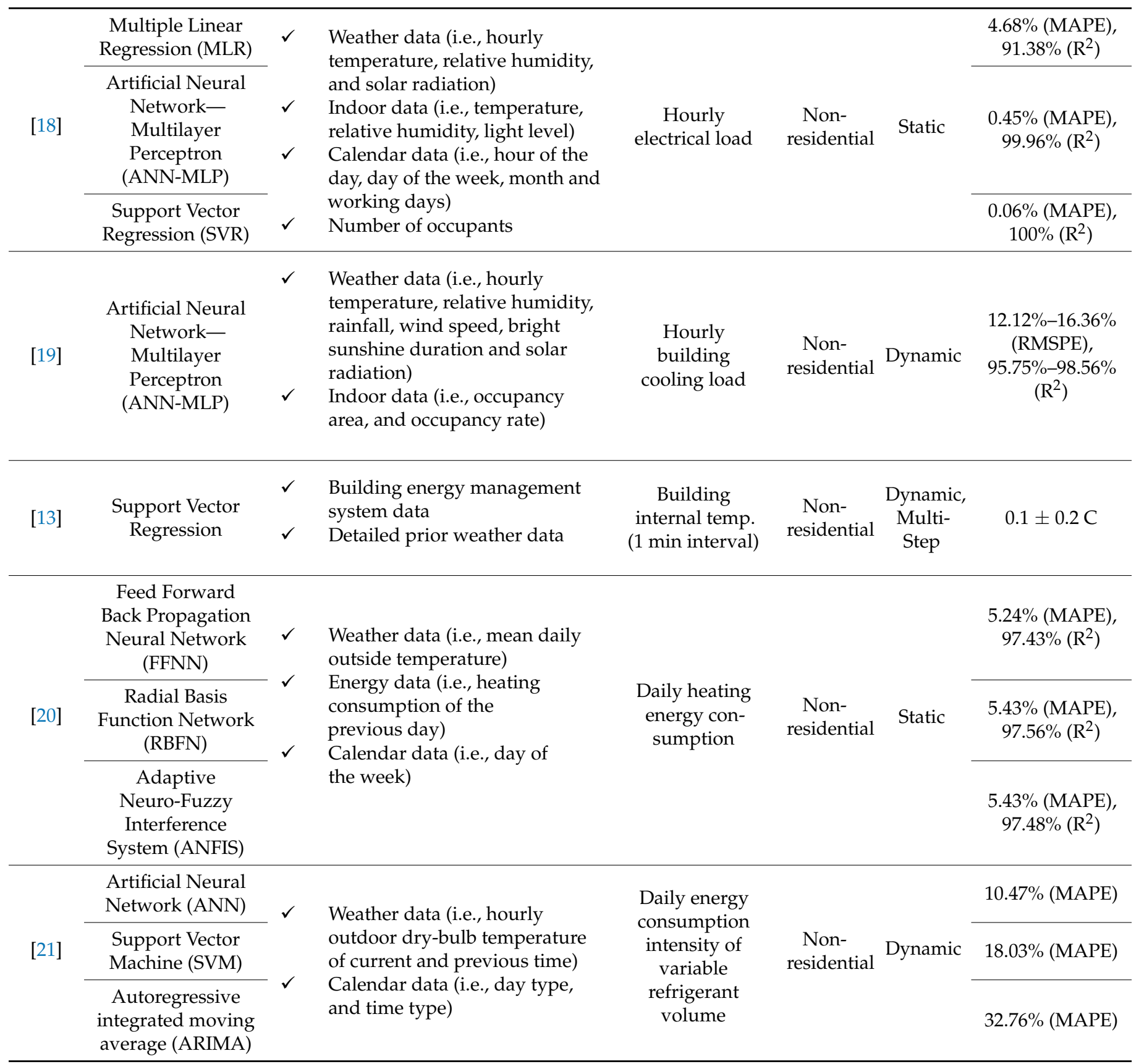

All of these machine learning models have used as predictors different weather, indoor, building, and calendar inputs. The weather data used included dry bulb temperature ([14-21]), relative humidity, and solar radiation ([17-19]). An hourly weather data frequency was used by Al Tarhuni et al. [14], Li et al. [17], Massana et al. [18], Kwok et al. [19], and Zhao et al. [21], whereas Özmen et al. [15], Iwafune et al. [16], and Jovanovic et al. [20] relied upon daily data.

Several researchers used building envelope data to improve the models. Al Tarhuni et al. [14] relied upon knowledge of the insulation characteristics of the walls, attic, and windows. Li et al. [22] and Ekici et al. [23] included information about the thermal inertia of building. Additionally, Li et al. [22], and Ekici et al. [23] added extra information about the residences shading and building transparency ratios.

A number of the researchers used building geometry and energy system characteristics as predictors. For example, Al Tarhuni et al. [14] used furnace efficiency, water heater 
energy factor, and Seasonal Energy Efficiency Ratio (SEER) value for the cooling system as predictors.

Lastly, relative to the predictors employed, a number of researchers used prior energy consumption data in various forms. Al Tarhuni et al. [14] utilized prior monthly energy consumption data to predict future consumption. Özmen et al. [15] developed a model for a specific city to estimate natural gas consumption for one-day ahead using the previous day, six, seven, and 14 days of natural gas consumption. Similarly, Jovanovic et al. [20] employed previous day consumption to forecast energy consumption for one day ahead.

In terms of approaches employed, the techniques used have been quite diverse. Most of the researchers evaluated the performance of at least one type of Artificial Neural Network (ANN). For instance, Ekici et al. [23] developed an Artificial Neural Network-Back Propagation (ANN-BP) model to predict annual building heating energy. Kwok et al. [19] predicted hourly building cooling load using only Artificial Neural Network-Multilayer Perceptron (ANN-MLP). Moreover, Li et al. [22] evaluated the performance of three types of ANN including Artificial Neural Network-Back Propagation (ANN-BP), Artificial Neural Network-Radial Basis Function (ANN-RBF), Artificial Neural Network-General Regression (ANN-GR), as well as Support Vector Machine (SVM). Another study by Li et al. [17] developed a predictive model to estimate hourly building cooling load based on the Support Vector Machine (SVM) and Artificial Neural Network-Back Propagation (ANN-BP) techniques. Massana et al. [18] estimated hourly building electric load based on Multiple Linear Regression (MLR), Artificial Neural Network-Multilayer Perceptron (ANN-MLP) and Support Vector Regression (SVR). Multiple Linear Regression (MLR), Random Forest Regression (RF), Gradient Boosting Machine (GBM), and other algorithms were used as well. Villa and Sassanelli likewise employed a dynamic multi-step approach to predict internal temperature in a building. Their approach leverage a Support Vector Machine algorithm. Their reported accuracy was exceptional $\left(0.1 \pm 0.2^{\circ} \mathrm{C}\right)$ [13].

A large number of studies used a static modeling approach including those by Al Tarhuni et al. [14], Özmen et al. [15], Li et al. [22], Iwafune et al. [16], Ekici et al. [23], Massana et al. [18], and Jovanovic et al. [20], while Li et al. [17] used dynamic model. On the other hand, Kwok et al. [19], and Zhao et al. [21] used a multi-step model approach.

Finally, in terms of predictive accuracy, one trend is apparent. Use of hourly information to predict energy consumption at higher frequency (e.g., sub-hourly or hourly) yields better predictive models. The best of these employed models relies upon prior consumption data to predict future consumption (Özmen et al. [15], R-squared value $>0.989$, Jovanovic et al. [20], R-squared value $>0.972$, Villa and Sassanelli [13], temperature prediction accuracy of $0.1 \pm 0.2^{\circ} \mathrm{C}$ ).

This research builds upon the prior efforts to predict monthly energy consumption, by leveraging for the first time the burgeoning and much more readily available higher frequency smart WiFi thermostat. Given that models employing to predict energy consumption where data is available at smaller periods than monthly, the additional bandwidth afforded from use of thermostat data offers hope for improving energy consumption prediction and therefore energy savings prediction in residences subject to monthly metering.

Specifically, this research combines thermostat data and derived thermostat data in the form of power spectral density data developed from the measured thermostat temperature with other data features which have already been shown to yield quality energy consumption predictions, including geometrical, energy characteristics, and occupancy, and weather data. Table 2 documents the input features used in this study, subset into features used prior and new features considered here. The new features included in this study the thermostat derived features and the binned input weather features employed previously by Alanezi et al. [24] which considered the statistical variation of the weather features developed for each energy meter period. 
Table 2. Features used to predict consumption as categorized by prior use and new additions.

\begin{tabular}{|c|c|c|}
\hline Study & Data Title & Used \\
\hline \multirow{10}{*}{ Prior } & Monthly weather features & \\
\hline & Indoor temperatures & \\
\hline & Building geometrical & $\sqrt{ }$ \\
\hline & Building envelope & $\sqrt{ }$ \\
\hline & Energy system characteristics & $\sqrt{ }$ \\
\hline & Historical energy consumption & $\sqrt{ }$ \\
\hline & Heating Degree Days (HDD) & \\
\hline & Calendar & \\
\hline & Geography & \\
\hline & Number of occupants & $\sqrt{ }$ \\
\hline \multirow{4}{*}{ New } & Statistical variation of the outdoor temperature & $\sqrt{ }$ \\
\hline & Power spectrum density from thermostat temperature & $\sqrt{ }$ \\
\hline & Questionnaire with regards to the presence of a washer/dryer & $\sqrt{ }$ \\
\hline & Questionnaire with regards to the presence of a dishwasher & $\sqrt{ }$ \\
\hline
\end{tabular}

\section{Methodology}

The methodology employed to both estimate energy savings and predict consumption follows. Step 1 in the process is the collection and preparation of data. The data includes thermostat derived information, geometrical and energy consumption, and weather data aligned with energy consumption. Step 2 in the process involves the development and testing of machine-learning based static models to improve the prediction of monthly energy consumption of any residence (using a singular model) relative to prior work. This process above all seeks to demonstrate the value of smart WiFi thermostat derived data in predicting consumption. Finally, the last step involves application of the developed model to estimate savings in real residences. Most importantly in this step, the methodology describes how the uncertainty in estimating savings is quantified in order to validate potential improvements in resolving smaller percentage savings than achievable with the currently employed ASHRAE inverse-modeling toolkit.

\subsection{Collection and Preparation of Data with New Thermostat Derived Predictors}

This study considered 101 houses owned by a university in the Midwest region of the US. Detailed energy audits were conducted on these houses during the summer 2015 [14] and again in the summer of 2020 to validate the original assessment and to validate energy efficiency upgrades to some of these residences. As described previously [24], this set of houses offered variety in size, insulation, and energy effectiveness, which is necessary for developing a generalizable single model capable of predicting the energy consumption of any residence.

Overall, the data employed for model development includes historical monthly energy consumption data for each residence, weather data obtained via the NOAA's National Climate Data Online resource [25], geometrical data obtained from the local county auditor public data, and smart WiFi thermostat data for each of the residences. All of this data is attainable remotely. Additionally, energy characteristics associated with insulation amount in the walls and ceiling, heating/cooling/water heating efficiencies, and occupancy data were included as predictors in order to ascertain their necessity in developing accurate models. Ideally the goal of this research is to show that accurate energy consumption and energy savings predictions can be achieved without on-site energy audit information.

In the summer of 2019, attic insulation was added to two of the included in this study. Smart WiFi thermostat data and natural gas consumption pre- and post-upgrade 
were available. Table 3 shows the attic R-Value before and after the retrofit for these two residences.

Table 3. Upgraded houses attic R-Value information.

\begin{tabular}{ccc}
\hline \multirow{2}{*}{ House Number } & \multicolumn{2}{c}{ Attic R-Value $\left(\mathbf{m}^{\mathbf{2}} \mathbf{K ~ W}^{-\mathbf{1}}\right)$} \\
\cline { 2 - 3 } & Before & Upgraded \\
\hline House 1 & 1.13 & 3.34 \\
\hline House 2 & 3.13 & 3.34 \\
\hline
\end{tabular}

Data preprocessing is necessary to develop an appropriate dataset for creating an accurate model, regardless of the application. Moreover, effective data preprocessing plays an important role in the development of machine learning models by improving the data sample quality [26]. The data preprocessing here follows that described in prior work [24]. The most critical steps are (i) creating power spectra from the uniformly spaced, measured thermostat interior temperature data; (ii) establishing histograms of the outdoor temperature for each meter period; (iii) synching data according to the time stamp and address; and (iv) elimination of similar houses to prevent model bias for such residences.

Most critical to this study is the creation of histograms from power spectra of the interior temperature obtained from the smart WiFi thermostat data for each individual residence. Effectively this data provides evidence of the thermal dynamics of the residences. Alanezi et al. [24] had shown previously the value of this processed thermostat data in the prediction of building energy characteristics. Then, this data was merged with historical energy consumption data with synched weather data, and unique geometrical and energy characteristics for each of the residences, all in one data file, thus permitting development of a singular model capable of applicability to all residences.

\subsection{Model Development to Predict Monthly Consumption Using Thermostat Derived Data}

The selection of an appropriate machine learning algorithm depends on data type, number of observations, and number of input features. Multiple machine learning modeling algorithms should be considered. Application of any technique also requires tuning of hyperparameters. In order to produce the best models, the hyperparameters controlling the different machine learning algorithms need to be optimized. For example, the major hyperparameters in Random Forest (RF) models are number of trees, maximum number of features considered for splitting a node, maximum number of levels in each decision tree, minimum number of data points placed in a node before the node is split, and minimum number of data points allowed in a leaf node, etc. $[27,28]$. This research employed the AutoML $\mathrm{H}_{2} \mathrm{O}$ package [29] to evaluate different machine learning model performance in predicting monthly natural gas consumption utilizing the acquired and processed data described in the previous sub-sections. The considered algorithms included Random Forest, Extremely Randomized Tree, Gradient Boosting Machine (GBM), Extreme Gradient Boosting (XGBoost), Deep Neural Network, and Stacked Ensemble. Table 4 shows the input features employed to predict monthly gas consumption.

The model performance for both validation and testing was evaluated using root mean squared error (RMSE), mean absolute error (MAE), mean absolute percentage error (MAPE), and R-squared metric. RMSE, MAE, and R-squared parameters can be shown respectively as follows:

$$
\begin{gathered}
R M S E=\sqrt{\frac{1}{N} \sum_{i=1}^{N}\left(y_{i}-\hat{y}_{i}\right)^{2}}=\sqrt{M S E}, \\
M A E=\frac{1}{N} \sum_{i=1}^{N}\left|y_{i}-\hat{y}_{i}\right|,
\end{gathered}
$$




$$
\begin{gathered}
\text { MAPE }=\frac{1}{N} \sum_{i=1}^{N}\left|\frac{y_{i}-\hat{y}_{i}}{y_{i}}\right|, \\
R^{2}=1-\frac{M S E(\text { model })}{M S E(\text { baseline })}=\frac{\frac{1}{N} \sum_{i=1}^{N}\left(y_{i}-\hat{y}_{i}\right)^{2}}{\frac{1}{N} \sum_{i=1}^{N}\left(y_{i}-\bar{y}_{i}\right)^{2}},
\end{gathered}
$$

Table 4. Input features used to develop the model.

\begin{tabular}{lcc}
\hline \multicolumn{1}{c}{ Input Features } & Input & Output \\
\hline Floor area $\left(\mathrm{m}^{2}\right)$ & $\mathrm{X}$ & $\mathrm{X}$ \\
Basement $\mathrm{area}^{2}\left(\mathrm{~m}^{2}\right)$ & $\mathrm{X}$ & $\mathrm{X}$ \\
Attic area $\left(\mathrm{m}^{2}\right)$ & $\mathrm{X}$ & $\mathrm{X}$ \\
Window area $\left(\mathrm{m}^{2}\right)$ & $\mathrm{X}$ \\
Wall area $\left(\mathrm{m}^{2}\right)$ & $\mathrm{X}$ \\
\hline Attic thermal insulation $\left(\mathrm{m}^{2} \mathrm{~K} \mathrm{~W}^{-1}\right)$ & $\mathrm{X}$ \\
Walls thermal insulation $\left(\mathrm{m}^{2} \mathrm{~K} \mathrm{~W}^{-1}\right)$ & $\mathrm{X}$ \\
Furnace efficiency (-) & $\mathrm{X}$ \\
Water heater efficiency $(-)$ & $\mathrm{X}$ \\
\hline Is there a wash and dryer machine (yes/no) & $\mathrm{X}$ \\
Is there a dishwasher machine (yes/no) & $\mathrm{X}$ \\
\hline Number of occupants & \\
\hline Probability density bins for outdoor temperature for & \\
individual meter periods & \\
\hline Power spectrum bins for indoor temperature (PSD Freq) & \\
\hline Monthly gas usage (MJ month & \\
\hline
\end{tabular}

\subsection{Measurement of Energy Savings from Improved Means to Predict Consumption}

To estimate the savings from energy-efficiency upgrades, step 1 was to collect and organize new energy consumption data $\left(E_{a}\right)$ for the upgraded residences post-retrofit and develop the needed weather inputs for the new meter periods. Step 2 was to apply the developed model to these residences using this weather data as inputs and the derived thermostat data pre-retrofit to predict consumption post-upgrade, $P$. Step 3 was to forecast energy consumption for the new meter periods using the developed model. The forecast energy consumption effectively represents the energy consumption were no upgrade to have been made. Lastly, in step 4 the actual energy consumption is compared to the forecasted energy consumption based upon the pre-retrofit model in order to predict savings.

$$
\% \text { Savings, predicted }=S=\frac{\mid \text { Predicted Consumption }- \text { Actual Consumption } \mid}{\mid \text { Precicted Consumption } \mid} \times 100 \% \text {, }
$$

The derived savings from the upgrade is only dependent upon the savings in heating energy. Water heating energy should remain roughly the same. The uncertainty in the savings estimation inevitably depends upon the error associated with estimating consumption, according to

$$
\delta_{\text {savings }}=\frac{d S}{d P} \delta P=\frac{E_{a}}{P^{2}} \delta P,
$$

Thus, if the uncertainty in measuring energy consumption can be estimated, then so too can the error in estimating energy savings be estimated.

\section{Results}

In this section, results are reported to (1) assess the value of smart WiFi thermostat derived information in the form of residence power spectra bins in improving the prediction of monthly energy consumption; and (2) demonstrate the potential of employing the 
developed model to improve the accuracy of energy savings predictions and the ability to resolve smaller percentage savings from energy system upgrades in residences.

\subsection{Assessing the Importance of Thermostat-Derived Data in Improving Prediction of Monthly Energy Consumption}

First, all predictors (residential building geometry, energy characteristics, and occupancy, thermostat derived power spectra data, and monthly probability density of outdoor temperature) were considered in developing a singular model representing all residences in the study using the $\mathrm{H} 2 \mathrm{O}$ AutoML toolkit [29] to predict the monthly gas consumption for all residences. A variable importance plot was developed for the best model obtained, shown in Figure 1. Of note in this figure is that while the geometrical characteristics associated with the wall and attic areas are deemed most important, the power spectrum features (indicated as PSD Freq.X) are also very important. In fact, a number of the frequency bins are deemed more important than energy characteristic features such as the attic and wall R-Values. Most importantly, these features can be derived from the thermostat data alone; potentially mitigating the need to collect energy characteristics for the residence from on-site assessments.

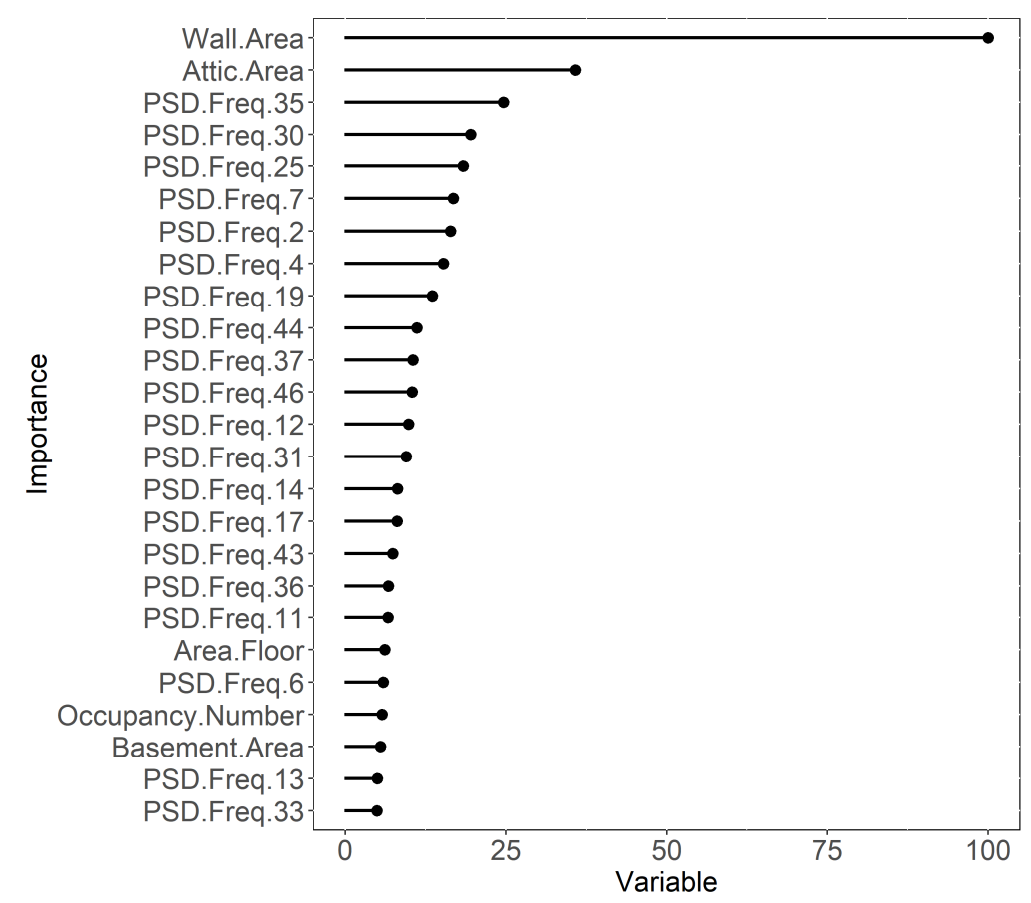

Figure 1. Variable importance plots including thermostat derived information for natural gas consumption model.

\subsubsection{Development of Best Model to Predict Energy Consumption}

The GBM model showed outstanding prediction accuracy. Table 5 shows the error metrics from the testing dataset for the best models developed using this machine learning algorithm for subsets of the input features available. The predictor subsets considered for model development are documented in the table below. Additionally included are the error metrics. The MAE and RMSE error metrics are based upon energy consumption for whole year. In this table, Case (a) includes as predictors only geometrical and outdoor temperature probability density bin values. Case (b) adds consideration of both number of occupants and energy system characteristics data. It is clear that the addition of these features improved the model performance considerably. Case (c) adds questionnaire data with regards to the presence of a washer/dryer and dishwasher. The addition of this data did little to improve the model. Case (d) adds all thermostat measured indoor temperature power spectrum data. Again, there is significant improvement in the model from these 
input features. Thus, thermostat data conclusively improves the ability to accurately model monthly energy consumption. Case (e) considers only the top five frequency bins of the power spectra information obtained from a variable importance analysis. The model performance actually deteriorates. Case (f) adds six frequency bins used to predict energy characteristics (attic R-Value, walls R-Value, furnace efficiency, and AC SEER) by Alanezi et al. [24]. These frequencies were shown in this prior study to best enable accurate prediction of the actual energy characteristics for a residence. The model performance for this case is seen to improve markedly; the R-squared value is 0.9519 and the MAE is 996.52. In Case (g) the energy characteristics and occupancy data are removed from this best model. The model performance is noted to have declined considerably. Thus, while the goal was to develop a model that would require no on-site collected data, it is clear that such data is valuable in terms of producing an accurate model for estimating energy consumption, and likewise energy savings (see Equation (6)).

Table 5. Feature selection cases with model prediction evaluation parameters for the testing dataset.

\begin{tabular}{|c|c|c|c|c|c|}
\hline Case & Feature Types & $\mathbf{R}^{2}$ & RMSE & $\begin{array}{l}\text { MAE, Annual Gas } \\
\text { Consumption (MJ) }\end{array}$ & MAPE \\
\hline (a) & $\begin{array}{l}\text { geometrical and outdoor temperature } \\
\text { probability density bin }\end{array}$ & 0.7533 & 2724.36 & 2319.08 & 0.2191 \\
\hline (b) & $\begin{array}{l}\text { geometrical, outdoor temperature } \\
\text { probability density bin, number of } \\
\text { occupants, and energy } \\
\text { system characteristics }\end{array}$ & 0.8641 & 1993.98 & 1641.50 & 0.1644 \\
\hline (c) & $\begin{array}{l}\text { geometrical, outdoor temperature } \\
\text { probability density bin, number of } \\
\text { occupants, energy system characteristics, } \\
\text { and questionnaire }\end{array}$ & 0.8646 & 1939.65 & 1602.43 & 0.1644 \\
\hline (d) & $\begin{array}{l}\text { geometrical, outdoor temperature } \\
\text { probability density bin, number of } \\
\text { occupants, energy system characteristics, } \\
\text { questionnaire, and all PSD bins }\end{array}$ & 0.9109 & 1673.73 & 1413.29 & 0.1650 \\
\hline (e) & $\begin{array}{l}\text { geometrical, outdoor temperature } \\
\text { probability density bin, number of } \\
\text { occupants, energy system characteristics, } \\
\text { questionnaire, and top five PSD } \\
\text { frequency bins }(35,30,25,7 \text {, and } 2)\end{array}$ & 0.8867 & 1770.57 & 1415.60 & 0.1561 \\
\hline (f) & $\begin{array}{l}\text { geometrical, outdoor temperature } \\
\text { probability density bin, number of } \\
\text { occupants, energy system characteristics, } \\
\text { questionnaire, and six PSD frequency } \\
\text { bins }(6,13,16,23,24 \text { and } 46)\end{array}$ & 0.9519 & 1234.80 & 996.52 & 0.1465 \\
\hline (g) & $\begin{array}{l}\text { geometrical, outdoor temperature } \\
\text { probability density bin, number of } \\
\text { occupants, questionnaire, and six PSD } \\
\text { frequency bins }(6,13,16,23,24 \text { and } 46)\end{array}$ & 0.8881 & 1728.65 & 1396.56 & 0.1586 \\
\hline
\end{tabular}

Overall, the best model (case $\mathrm{f}$ ) yielded an average residential consumption over this time frame of $11,463 \mathrm{MJ}$, associated with a mean error in predicting monthly energy consumption for all of the residences considered of $\pm 8.69 \%$. The associated R-squared value is 0.9519 . This prediction is better than the best to date in terms of predicting monthly energy consumption (Altarhuni et al.; R-squared value $=0.94$, [14]). It should be noted that Altarhuni's approach used a regression of monthly energy data for each residence against monthly average outdoor temperature to derive predictors which could be used in a singular model to predict consumption of any residence. So, in effect, it used energy data 
to develop predictive features to predict energy consumption. The approach developed here does not do this.

\subsubsection{Best Model Testing Results}

The best model developed for Case $\mathrm{f}$ above, was tested on six residences not used in the training of the model. The testing results for these six residences are shown in Table 6 . The R-squared and MAE values for predicting the monthly natural gas usage were respectively $0.9472,0.9485,0.9725,0.9201,0.9788$, and 0.9446 (R-squared), and 1073.18, $910.01,646.85,1678.40,613.37$, and 1057.32 MJ (MAE). These results illustrate that the model predictive effectiveness is consistent with the validation metrics used in the training, helping to establish the generalizability of the model to new residential data.

Table 6. Model prediction evaluation parameters for testing dataset.

\begin{tabular}{ccccc}
\hline Target & $\mathbf{R}^{\mathbf{2}}$ & RMSE & MAPE & MAE \\
\hline Test House 1 & 0.9472 & 1406.42 & 0.1240 & 1073.18 \\
\hline Test House 2 & 0.9485 & 1306.15 & 0.0842 & 910.01 \\
\hline Test House 3 & 0.9725 & 913.75 & 0.0729 & 646.85 \\
\hline Test House 4 & 0.9201 & 1822.71 & 0.3276 & 1678.40 \\
\hline Test House 5 & 0.9788 & 743.02 & 0.1233 & 613.37 \\
\hline Test House 6 & 0.9446 & 1216.73 & 0.1470 & 1057.32 \\
\hline Average & 0.9519 & 1234.80 & 0.1465 & 996.52 \\
\hline
\end{tabular}

A time series plot of the monthly natural gas consumption as a function of time for the six test residences is shown in Figure 2. The figure compares both the actual and predicted consumption. It is clear that the two lines representing actual and predicted consumption correspond very well. Note that the actual and predicted values for each of the testing houses are shown in Table A1 at the Appendix A section.

\subsection{Estimating Savings and Quantifying Uncertainty in the Savings Predictions}

As noted previously, two of the residents included in the study received upgrades in terms of attic insulation. The estimated energy savings for one month of these two residences using Equation (5) are shown in Table 7. The results indicate the natural gas consumption savings from attic insulation upgrade for House 1 and 2 are respectively $21.5 \%$ and $15.3 \%$. Improvement to attic insulation in House 1 show significantly superior energy savings relative to House 2. The results are consistent with expectation, because House 1 no insulation prior to the upgrade, while House 2 had a very small amount of insulation. The uncertainty in the reported savings is respectively for House 1 and $2 \pm 4.18 \%$ and $\pm 6.26 \%$.

In an effort to generalize the results, the following questions are posed. What-if the energy savings is less? What percentage savings could we resolve? What percentage savings can be resolved?

Figure 3 shows a plot of the predicted savings (MJ) versus percentage savings for House 1 above were the actual savings to be less than that reported in Table 7. Error bars are shown to represent the uncertainty in predicting the savings (from Equation (5)). It is clear from this figure that as the percentage savings declines, the uncertainty in estimating savings increases slightly. It is also clear that accuracy in estimating savings declines. In fact, no savings can be resolved for savings percentages of less than roughly $5 \%$ based upon this approach. At this cut-off the uncertainty in estimating savings is approximately equal to the estimated savings. This savings resolution is valid for any residence, given that it derives from a model based upon a large number of residences. In comparison, the ASHRAE guideline for estimating savings from whole-building energy consumption at best renders an estimation of savings no less than $10 \%$ of total consumption. Thus, there 
is certainty that this approach renders substantial improvement in both the estimation accuracy of savings and the percentage savings which can be resolved.

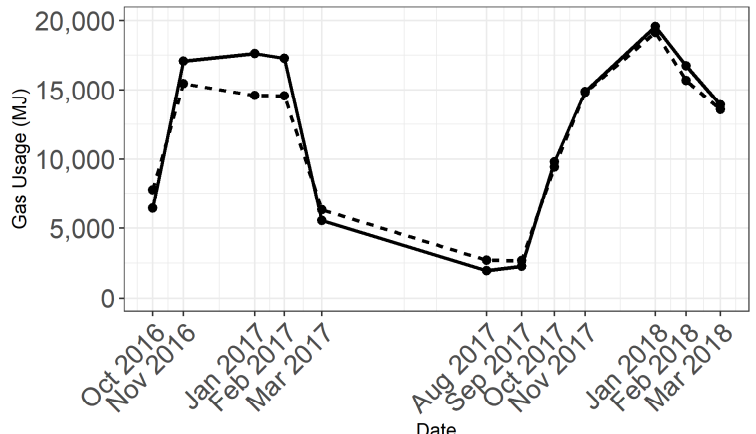

(a)

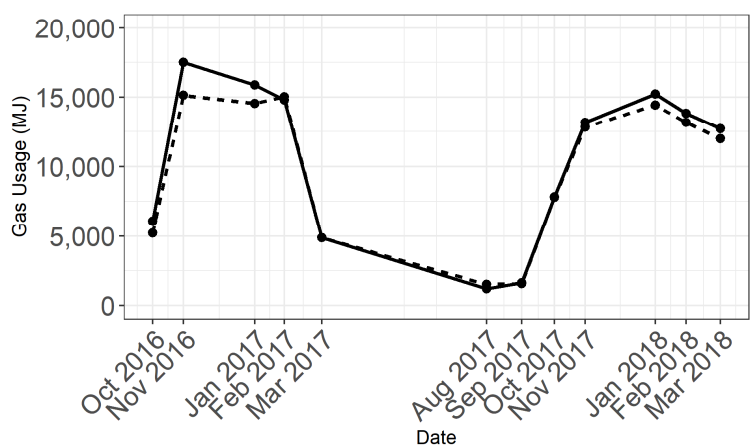

(c)

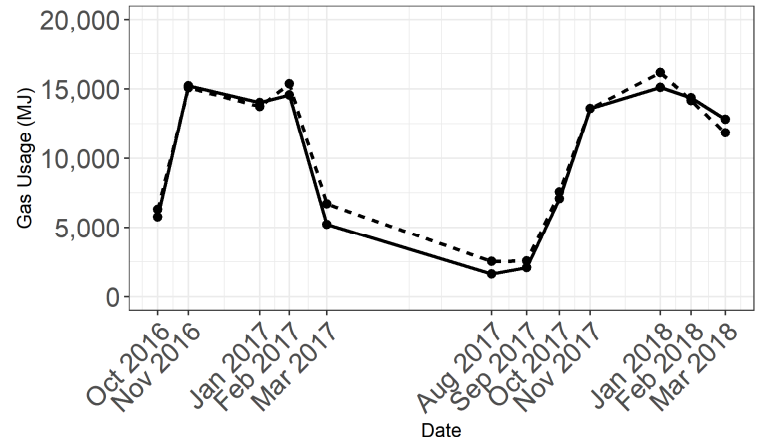

(e)

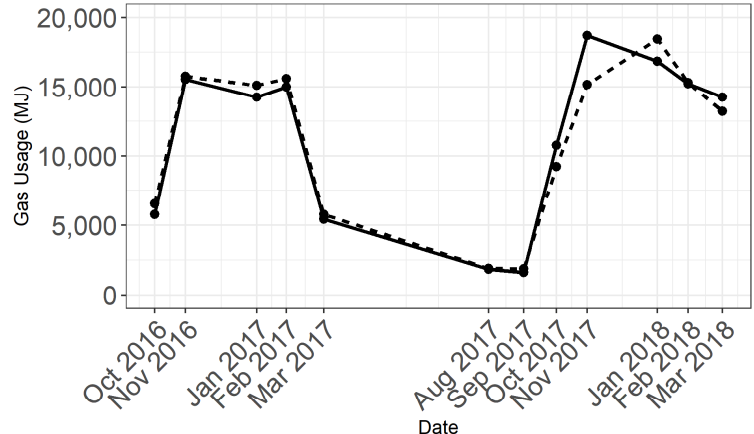

(b)

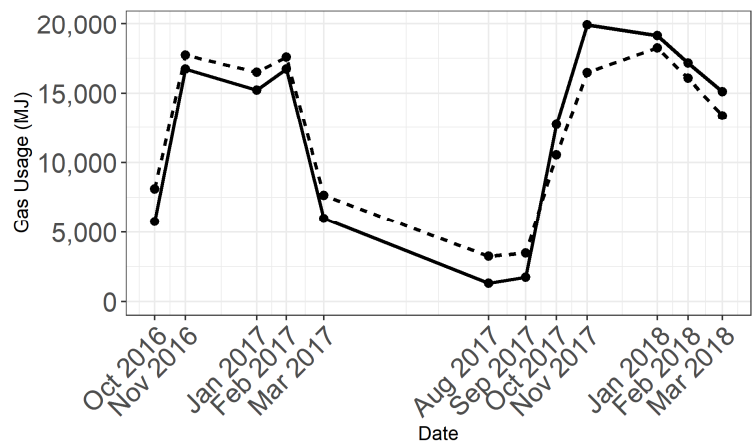

(d)

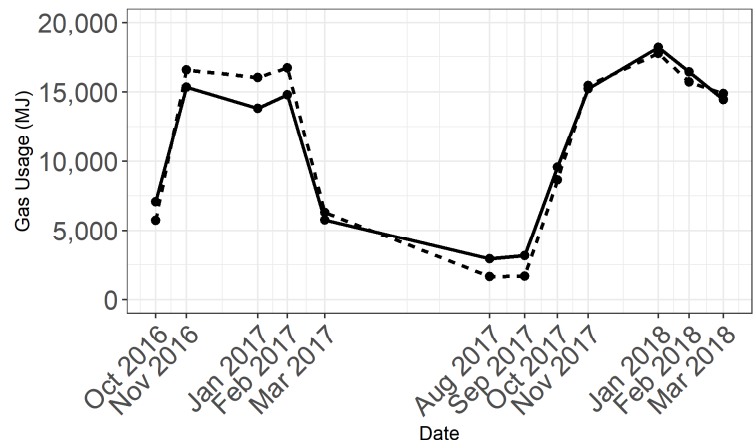

(f)

\section{- Actual -- Predicted}

Figure 2. Time series natural gas energy consumption plots for each of the testing houses: (a) House 1; (b) House 2; (c) House 3; (d) House 4; (e) House 5; and (f) House 6.

Table 7. Savings percentage and uncertainty for an attic retrofit.

\begin{tabular}{|c|c|c|c|c|c|c|}
\hline $\begin{array}{l}\text { House } \\
\text { Number }\end{array}$ & $\begin{array}{l}\text { Bill Month } \\
\text { Post-Retrofit }\end{array}$ & $\begin{array}{c}\text { Measured } \\
\text { Natural Gas } \\
\text { Consumption } \\
\text { (MJ) }\end{array}$ & $\begin{array}{c}\text { Predicted } \\
\text { Natural Gas } \\
\text { Consumption } \\
\text { Assuming no } \\
\text { Upgrade (MJ) }\end{array}$ & $\begin{array}{l}\text { Uncertainty in } \\
\text { Estimating } \\
\text { Consumption } \\
\left(\mathrm{MJ} \text { month }^{-1}\right)\end{array}$ & $\%$ Savings & $\begin{array}{l}\text { Uncertainty in } \\
\text { Estimating } \\
\text { Saving (\%) }\end{array}$ \\
\hline House 1 & \multirow{2}{*}{ December 2019} & $14,677.20$ & $18,712.95$ & \multirow{2}{*}{ \pm 996.52} & 21.57 & \pm 4.18 \\
\hline House 2 & & $11,415.60$ & $13,476.24$ & & 15.29 & \pm 6.26 \\
\hline
\end{tabular}




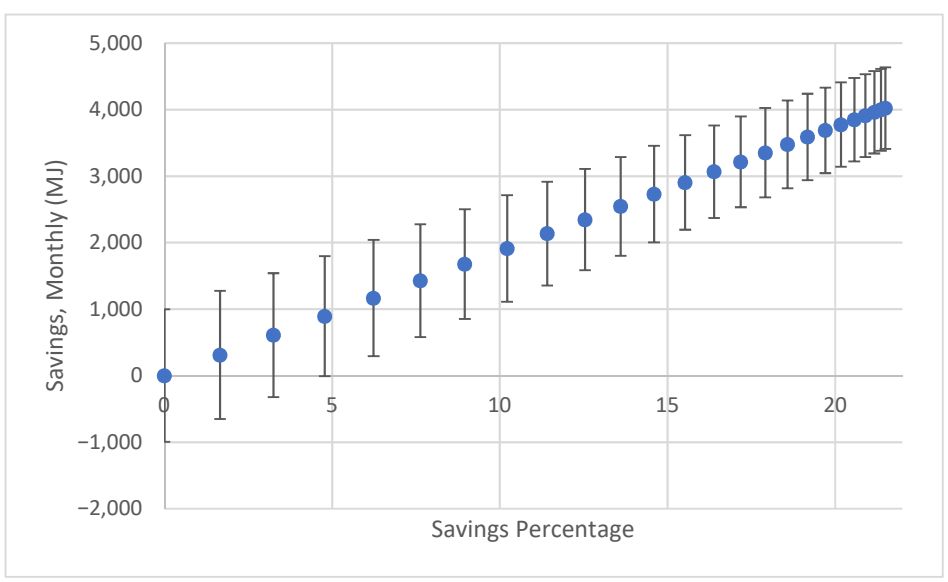

Figure 3. Plot of savings (MJ) versus percentage savings for House 1 with error bars associated with the uncertainty in estimating savings.

\section{Discussion and Conclusions}

This research presents an improved accuracy approach to predict monthly natural gas consumption for residential buildings from accessible residential building information, historical weather data, and archived smart WiFi thermostat data utilizing a machine learning-based approach. The singular model developed using data from a collection of residences can be used to accurately predict consumption and savings from upgrades or changes in behavior for any residence with geometrical and energy characteristics represented within the minimum-maximum bounds of the features of the residences included in the training. Specifically the approach employed, because of the use of data derived from high frequency smart WiFi data, yields a mean error rate of $\pm 8.69 \%$ for predicting annual consumption. Most significantly, for two houses for which insulation upgrades were implemented during the study period, savings estimation uncertainty was less than $\pm 7 \%$. This result shows the promise of the approach used here in estimating HVAC and envelope upgrades in any residence where monthly energy consumption is known, and smart WiFi thermostats are available. In fact, results are shown which demonstrate the ability to resolve energy savings of less than $5 \%$ for any residence. This is a big improvement upon the ASHRAE recommended guideline for estimating savings from whole-building energy consumption, where at best energy savings no less than $10 \%$ of total consumption can be resolved. It is expected that model improvement and therefore improvement in estimating both energy consumption and savings is possible through the addition of additional residential data.

With this technique, there is significant potential for implementing utility-scale programs to estimate consumption and measure savings from energy efficiency upgrades and/or behavior-based changes with accuracy. Precise savings estimates can help to validate value from all energy measures implemented in any house. The knowledge derived could help to inform more strategic energy reduction programs at a utility scale. Investment could be focused on measures having the potential for measurable savings.

Unfortunately, the results did not show that only remotely obtainable data were sufficient to yield high accuracy estimations of consumption and savings. The results showed a need to document wall and attic insulation amount and heating/cooling system efficiencies prior to an upgrade. This data likely requires on-site inspection.

Additionally, there are several notable limitations of this research and it can be future work to improve the study. First, it is necessary to expand the training dataset to contain a greater number of residences and more variety in the residences included. The current training data did not include very large and very small residences. Nor did it contain any stone, stucco, or brick residences. Second, the training data should use more behavioral information derive from smart WiFi thermostat including thermostat temperature set point history. Lastly, this approach was tested only in a single climatic region. In order to develop 
truly generalizable models applicable to anywhere, it is essential to broaden the location of the residences included in the singular model training data.

Author Contributions: Conceptualization, A.A. and K.P.H.; methodology, A.A. and K.P.H.; software, A.A. and R.E.; validation, A.A. and K.P.H.; formal analysis, A.A.; investigation, A.A. and R.E.; resources, A.A. and K.P.H.; data curation, A.A. and K.P.H.; writing-original draft preparation, A.A.; writing-review and editing, K.P.H.; visualization, A.A.; supervision, K.P.H.; project administration, K.P.H. All authors have read and agreed to the published version of the manuscript.

Funding: This research received no external funding.

Institutional Review Board Statement: Not applicable.

Informed Consent Statement: Not applicable.

Data Availability Statement: The data are not publicly available due to privacy.

Conflicts of Interest: The authors declare no conflict of interest.

\section{Appendix A}

Table A1. Actual and predicted data for 12 months of the testing houses using the best model.

\begin{tabular}{|c|c|c|c|c|c|c|}
\hline \multirow{2}{*}{ Date } & \multicolumn{2}{|c|}{ House 1} & \multicolumn{2}{|c|}{ House 2} & \multicolumn{2}{|c|}{ House 3} \\
\hline & Actual & Predicted & Actual & Predicted & Actual & Predicted \\
\hline Oct-16 & 6414 & 7757 & 5762 & 6549 & 6088 & 5229 \\
\hline Nov-16 & 17,069 & 15,463 & 15,546 & 15,760 & 17,503 & 15,136 \\
\hline Jan-17 & 17,612 & 14,589 & 14,242 & 15,107 & 15,873 & 14,537 \\
\hline Feb-17 & 17,286 & 14,580 & 15,003 & 15,607 & 14,785 & 15,031 \\
\hline Mar-17 & 5544 & 6321 & 5436 & 5779 & 4892 & 4881 \\
\hline Aug-17 & 1956 & 2721 & 1848 & 1920 & 1195 & 1516 \\
\hline Sep-17 & 2283 & 2682 & 1630 & 1880 & 1630 & 1565 \\
\hline Oct-17 & 9784 & 9424 & 10,763 & 9229 & 7827 & 7796 \\
\hline Nov-17 & 14,894 & 14,825 & 18,699 & 15,162 & 13,155 & 12,821 \\
\hline Jan-18 & 19,569 & 19,127 & 16,851 & 18,465 & 15,220 & 14,417 \\
\hline Feb-18 & 16,742 & 15,693 & 15,220 & 15,303 & 13,807 & 13,157 \\
\hline Mar-18 & 13,916 & 13,578 & 14,242 & 13,224 & 12,720 & 11,980 \\
\hline \multirow{2}{*}{ Date } & \multicolumn{2}{|c|}{ House 4} & \multicolumn{2}{|c|}{ House 5} & \multicolumn{2}{|c|}{ House 6} \\
\hline & Actual & Predicted & Actual & Predicted & Actual & Predicted \\
\hline Oct-16 & 5762 & 8108 & 5762 & 6302 & 7066 & 5737 \\
\hline Nov-16 & 16,742 & 17,721 & 15,220 & 15,087 & 15,329 & 16,560 \\
\hline Jan-17 & 15,220 & 16,496 & 14,024 & 13,737 & 13,807 & 16,027 \\
\hline Feb-17 & 16,742 & 17,606 & 14,568 & 15,366 & 14,785 & 16,702 \\
\hline Mar-17 & 5979 & 7654 & 5218 & 6703 & 5762 & 6291 \\
\hline Aug-17 & 1304 & 3241 & 1630 & 2523 & 2935 & 1641 \\
\hline Sep-17 & 1739 & 3473 & 2065 & 2561 & 3152 & 1683 \\
\hline Oct-17 & 12,720 & 10,528 & 7066 & 7570 & 9567 & 8646 \\
\hline Nov-17 & 19,895 & 16,484 & 13,590 & 13,586 & 15,220 & 15,434 \\
\hline Jan-18 & 19,134 & 18,237 & 15,112 & 16,157 & 18,156 & 17,737 \\
\hline Feb-18 & 17,177 & 16,091 & 14,351 & 14,159 & 16,416 & 15,694 \\
\hline Mar-18 & 15,112 & 13,367 & 12,828 & 11,846 & 14,459 & 14,882 \\
\hline
\end{tabular}




\section{References}

1. U.S. Energy Facts Explained. U.S. Energy Information Administration (EIA), 7 May 2020. Available online: https://www.eia. gov / energyexplained/us-energy-facts/ (accessed on 18 October 2020).

2. Amasyali, K.; El-Gohary, N.M. A review of data-driven building energy consumption prediction studies. Renew. Sustain. Energy Rev. 2018, 81, 1192-1205. [CrossRef]

3. Jacobson, M.Z.; Delucchi, M.A.; Bauer, Z.A.; Goodman, S.C.; Chapman, W.E.; Cameron, M.A.; Bozonnat, C.; Chobadi, L.; Clonts, H.A.; Enevoldsen, P.; et al. 100\% Clean and Renewable Wind, Water, and Sunlight All-Sector Energy Roadmaps for 139 Countries of the World. Joule 2017, 1, 108-121. [CrossRef]

4. Haberl, J.S.; Culp, C.; Claridge, D.E. ASHRAE's Guideline 14-2002 for Measurement of Energy and Demand Savings: How to Determine What Was Really Saved by the Retrofit. In Proceedings of the Fifth International Conference for Enhanced Building Operations, Pittsburgh, PA, USA, 11-13 October 2005.

5. Guideline 14-2002: Measurement of Energy and Demand Savings; ASHRAE: Atlanta, GA, USA, 2002.

6. Kissock, J.K.; Haberl, J.S.; Clarifge, D.E. Inverse Modeling Toolkit: Numerical Algorithms. ASHRAE Trans. 2003, 109, 425-434.

7. Inverse Modeling of Portfolio Energy Data for Effective Use with Energy Managers. In Proceedings of the 15th IBPSA Conference, San Francisco, CA, USA, 7-9 August 2017.

8. King, J. Energy Impacts of Smart Home Technologies; American Council for an Energy-Efficient Economy: Washington, DC, USA, 2018.

9. Lou, R.; Hallinan, K.P.; Huang, K.; Reissman, T. Smart Wifi Thermostat-Enabled Thermal Comfort Control in Residences. Sustainability 2020, 12, 1919. [CrossRef]

10. Huang, K.; Hallinan, K.P.; Lou, R.; Alanezi, A.; Alshatshati, S.; Sun, Q. Self-Learning Algorithm to Predict Indoor Temperature and Cooling Demand from Smart WiFi Thermostat in a Residential Building. Sustainability 2020, 12, 7110. [CrossRef]

11. Mosavi, A.; Bahmani, A. Energy consumption prediction using machine learning: A review. Preprints 2019. [CrossRef]

12. Seyedzadeh, S.; Rahimian, F.P.; Glesk, I.; Roper, M. Machine learning for estimation of building energy consumption and performance: A review. Vis. Eng. 2018, 6, 5. [CrossRef]

13. Villa, S.; Sassanelli, C. The Data-Driven Multi-Step Approach for Dynamic Estimation of Buildings' Interior Temperature. Energies 2020, 13, 6654. [CrossRef]

14. Al Tarhuni, B.; Naji, A.; Brodrick, P.G.; Hallinan, K.P.; Brecha, R.J.; Yao, Z. Large scale residential energy efficiency prioritization enabled by machine learning. Energy Effic. 2019, 12, 2055-2078. [CrossRef]

15. Özmen, A.; Yllmaz, Y.; Weber, G.-W. Natural gas consumption forecast with MARS and CMARS models for residential users. Energy Econ. 2018, 70, 357-381. [CrossRef]

16. Iwafune, Y.; Yagita, Y.; Ikegami, T.; Ogimoto, K. Short-term forecasting of residential building load for distributed energy management. In Proceedings of the 2014 IEEE International Energy Conference (ENERGYCON), Cavtat, Dubrovnik, Croatia, 13-16 May 2014.

17. Li, Q.; Meng, Q.; Cai, J.; Yoshino, H.; Mochida, A. Applying support vector machine to predict hourly cooling load in the building. Appl. Energy 2009, 86, 2249-2256. [CrossRef]

18. Massana, J.; Pous, C.; Burgas, L.; Melendez, J.; Colomer, J. Short-term load forecasting in a non-residential building contrasting models and attributes. Energy Build. 2015, 92, 322-330. [CrossRef]

19. Kwok, S.S.; Yuen, R.K.; Lee, E.W. An intelligent approach to assessing the effect of building occupancy on building cooling load prediction. Build. Environ. 2011, 46, 1681-1690. [CrossRef]

20. Jovanovic, R.Z.; Sretenovic, A.A.; Zivkovic, B.D. Ensemble of various neural networks for prediction of heating energy consumption. Energy Build. 2015, 94, 189-199. [CrossRef]

21. Zhao, D.; Zhong, M.; Zhang, X.; Su, X. Energy consumption predicting model of VRV (Variable refrigerant volume) system in office buildings based on data mining. Energy 2016, 102, 660-668. [CrossRef]

22. Li, Q.; Ren, P.; Meng, Q. Prediction Model of Annual Energy Consumption of Residential Buildings. In Proceedings of the 2010 International Conference on Advances in Energy Engineering, Beijing, China, 19-20 June 2010.

23. Ekici, B.B.; Aksoy, U.T. Prediction of building energy consumption by using artificial neural networks. Adv. Eng. Softw. 2009, 40, 356-362. [CrossRef]

24. Alanezi, A.; Hallinan, K.P.; Brodrick, P.G.; Huang, K. Interviewees, Automated Residential Energy Audits Using a Smart WiFi Thermostat Enabled Data Mining Approach. Energy Build. 2021.

25. National Oceanic and Atmospheric Administration (NOAA). U.S. Department of Commerce. Available online: https://gis.ncdc. noaa.gov/maps/ncei/ (accessed on 16 August 2018).

26. Chakrabarty, A.; Mannan, S.; Çagin, T. Inherently Safer Design. In Multiscale Modeling for Process Safety Applications; ButterworthHeinemann: Oxford, UK, 2016; pp. 339-396.

27. Drori, I.; Liu, L.; Nian, Y.; Koorathota, S.C.; Li, J.S.; Moretti, A.K.; Freire, J.; Udell, M. AutoML using Metadata Language Embeddings. In Proceedings of the 33rd Conference on Neural Information Processing Systems, Vancouver, BC, Canada, 8-14 December 2019. 
28. Osman, H.; Ghafari, M.; Nierstrasz, O. Hyperparameter optimization to improve bug prediction accuracy. In Proceedings of the 2017 IEEE Workshop on Machine Learning Techniques for Software Quality Evaluation, Klagenfurt, Austria, 21 February 2017; pp. 33-38.

29. AutoML: Automatic Machine Learning. H2O.ai, 18 June 2020. Available online: https:/ / docs.h2o.ai/h2o/latest-stable/h2odocs/automl.html (accessed on 19 June 2020). 